\title{
Numerical simulations of fluidization dynamics in a hot model of a CLC process
}

\author{
Anna Żyłka ${ }^{1,}$, Jarosław Krzywański ${ }^{2}$, Tomasz Czakiert $^{1}$, Kamil Idziak $^{1}$, Krzysztof Kulicki ${ }^{1}$, Sylwia Jankowska ${ }^{1}$, \\ and Wojciech Nowak $^{3}$ \\ ${ }^{1}$ Czestochowa University of Technology, Faculty of Infrastructure and Environment, Institute of Advanced Energy \\ Technologies, J.H. Dabrowskiego 73, 42-200 Czestochowa, Poland \\ ${ }^{2}$ Jan Dlugosz University in Czestochowa, Institute of Technology and Safety Systems, Armii Krajowej 13/15, 42-200 \\ Czestochowa, Poland \\ ${ }^{3}$ AGH University of Science and Technology, Department of Thermal Machinery and Flow, Faculty of Energy and Fuels, \\ Czarnowiejska 50B, I, 30-054 Cracow, Poland.
}

\begin{abstract}
Chemical Looping Combustion (CLC) is one of the most promising alternatives for solid fuel combustion. $\mathrm{CO}_{2}$ concentration in the exhaust gas is high in CLC technology which enables high efficiency of $\mathrm{CO}_{2}$ capture from flue gas. The use of solid oxygen carriers is a characteristic feature of a CLC process. Oxygen carriers are mainly metal oxides which are characterized by high oxygen transfer capacity and high mechanical resistance.

Since the CLC technology is not sufficiently recognized due to its complexity the development of models with real conditions of the CLC equipment is of practical significance.

The paper presents numerical simulations of the dynamic fluidized bed for Chemical Looping Combustion using CeSFaMB software. The model was validated on the basis of the results obtained from experiments, which were carried out on the Fluidized-Bed Chemical-Looping-Combustion of Solid-Fuels (FB-CLC-SF) unit. The studies were conducted in air atmosphere at temperature of $850^{\circ} \mathrm{C}$. The validation of the $1.5 \mathrm{D}$ model showed that the maximum relative error between experiment and simulations results does not exceed $12 \%$.
\end{abstract}

\section{Introduction}

Burning of fossil fuels is one of the main sources of $\mathrm{CO}_{2}$ emissions into the atmosphere. It is therefore essential to develop new combustion technologies, which allows the use of fossil fuels while reducing $\mathrm{CO}_{2}$ emissions [1]. One of the interesting alternative to this problem is Chemical Looping Combustion (CLC). This technology is characterized by using solid oxygen carriers for fuel combustion [2]. The absence of air in the combustion chamber allows to obtain the exhaust gas containing mostly $\mathrm{CO}_{2}$ and $\mathrm{H}_{2} \mathrm{O}$ (Fig. 1). The almost pure $\mathrm{CO}_{2}$ is produced of the flue gas cleaning and condensation of steam. Therefore, the chemical looping combustion process allows to avoid expensive $\mathrm{CO}_{2}$ absorption installations $[3,4]$.

This paper presents the results of numerical simulations of the fluidization dynamics in a hot model of a CLC process which are a continuation of the previous works carried out on the cold model $[3,5]$.

The test units for cold and hot model (FB- CLC-SF) are located in Institute of Advanced Energy Technologies at the Czestochowa University of Technology and they were built in the framework of Polish - Norwegian research project NewLoop
"Innovative Idea for Combustion of Solid Fuels via Chemical Looping Technology" [6].

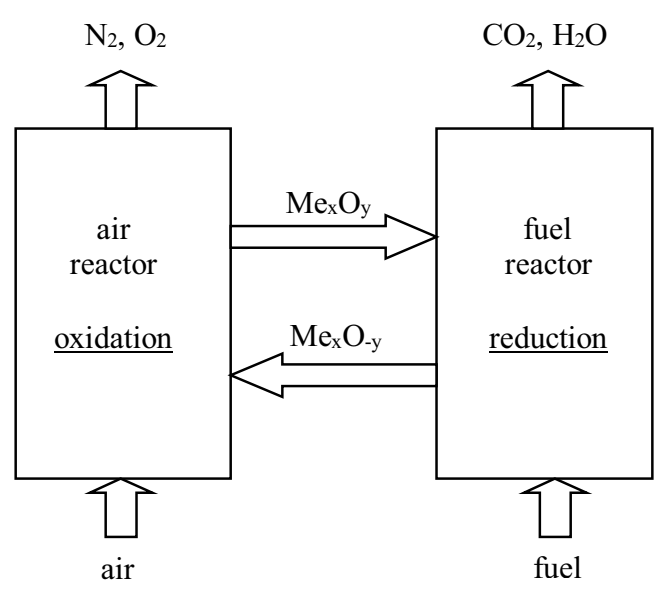

Fig. 1. The scheme of chemical looping combustion process [4]

\footnotetext{
${ }^{*}$ Corresponding author: azylka@is.pcz.pl
} 


\section{Materials and Methods}

\subsection{An object of investigations}

The innovative ideology of NewLoop project combines two complementary technologies: CLOU (Chemical looping with Oxygen Uncoupling) and iG-CLC (In-situ Gasification Chemical Looping), which create a so-called HCLC (Hybrid Chemical Looping Combustion). The CLOU process is characterized by the use of solid oxygen carrier, which does not require direct contact with the fuel to release oxygen in the fuel reactor. By contrast, the iG-CLC process requires that the oxygen carrier is in contact with the fuel $[5,7]$.

The experimental studies, as well as validation of the model were carried out on a Fluidized-Bed ChemicalLooping-Combustion of Solid-Fuels (FB-CLC-SF) unit (Fig. 2a). The system consists of two main circular contours. The first circular contour is composed of an air reactor with circulating fluidized bed, riser, cyclon and return system. The second circular contour consists of a fuel reactor with bubbling fluidized bed and particulate collector. (Fig. 2b). The main dimensions of the FB-CLC-SF unit are presented in Tables 1 and 2.

Table 1. The main dimensions of the fuel reactor

\begin{tabular}{|c|c|c|}
\hline & Chamber I & Chamber II \\
\hline $\begin{array}{c}\text { The inner equivalent diameter } \\
\text { of combustion chamber, [m] }\end{array}$ & 0.074 & 0.074 \\
\hline $\begin{array}{c}\text { The height of combustion } \\
\text { chamber, [m] }\end{array}$ & 0.500 & 0.500 \\
\hline
\end{tabular}

Table 2. The main dimensions of the air reactor and cyclon

\begin{tabular}{|c|c|}
\hline The diameter of the air reactor, [m] & 0.098 \\
\hline $\begin{array}{c}\text { The total height of the riser and air } \\
\text { reactor, [m] }\end{array}$ & 2.55 \\
\hline The diameter of the riser, [m] & 0.04 \\
\hline The efficiency of the cyclone, [\%] & 99 \\
\hline $\begin{array}{c}\text { The inner diameter of the cyclone, } \\
\text { [m] }\end{array}$ & 0.066 \\
\hline $\begin{array}{c}\text { The height of the cylindrical portion } \\
\text { of the cyclone, [m] }\end{array}$ & 0.190 \\
\hline $\begin{array}{c}\text { The height of the conical part of the } \\
\text { cyclone, [m] }\end{array}$ & 0.130 \\
\hline \begin{tabular}{c} 
The diameter of the downcomer, [m] \\
\hline
\end{tabular} & 0.028 \\
\hline
\end{tabular}

a)

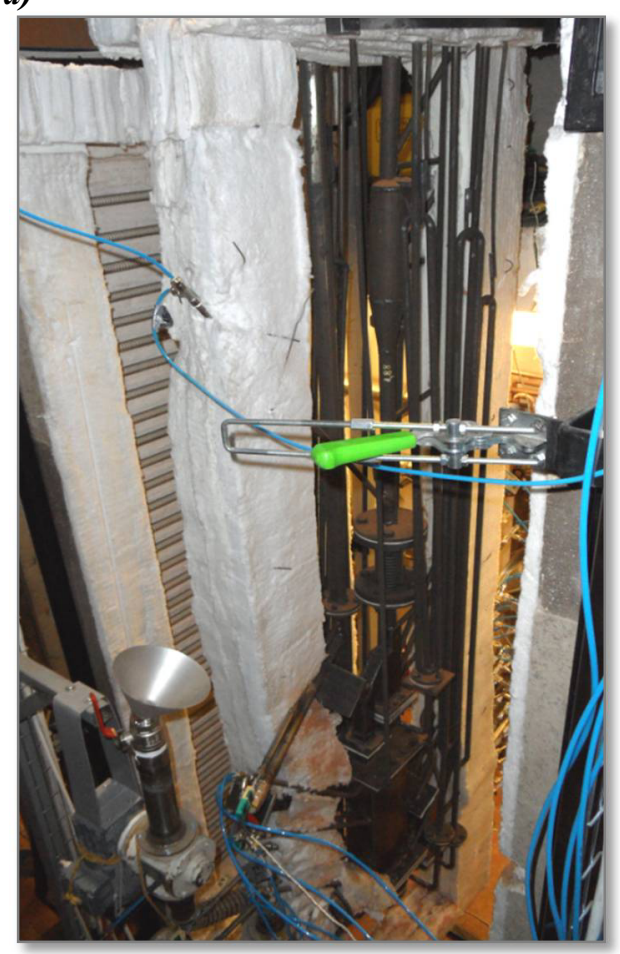

b)

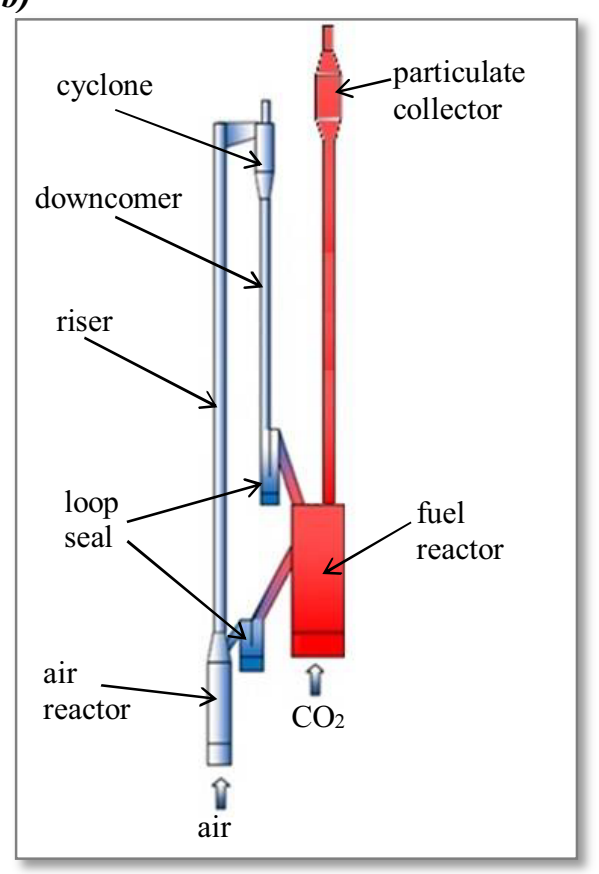

Fig. 2. The hot model ofFB-CLC-SF unit: (a) Photography of the FB-CLC-SF unit in the Institute of Advanced Energy Technology at the Czestochowa University of Technology; (b) The scheme of FB-CLC-SF unit [5]

\subsection{Research material}

The sand with the Sauter mean diameter of particles of $166 \mu \mathrm{m}$, true density of $3200 \mathrm{~kg} / \mathrm{m}^{3}$ and the sphericity of 0.7 are used during the investigations (Fig. 3). 


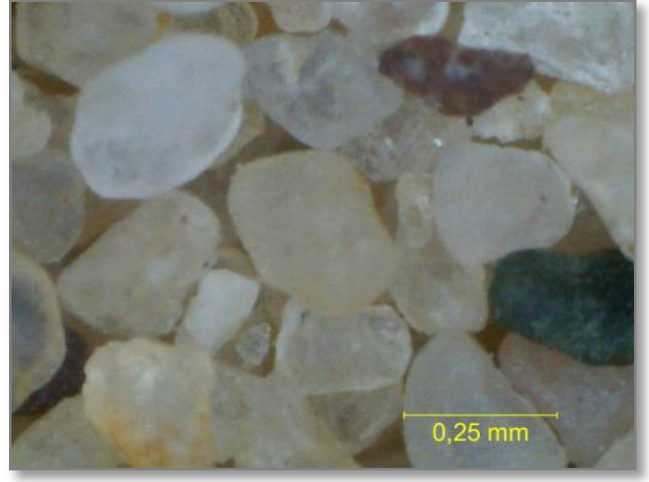

Fig. 3. Microscopic photograph of sand - research material used in the study

\subsection{Characteristics of CeSFaMB software}

The numerical simulations of the CLC process were carried out using the CeSFaMB software. (Comprehensive Simulator of Fluidized and Moving Bed equipment), which is especially dedicated to the modeling of fuel conversion implemented in bubbling and circulating fluidized bed (Fig. 4). CeSFaMB simulator requires the formulation of the so-called initial and boundary conditions. In order to confirm the reliability of the emerging model, both introduced and designated values should be verified by experimental studies. Otherwise, the results of the model calculations are purely hypothetical [5]

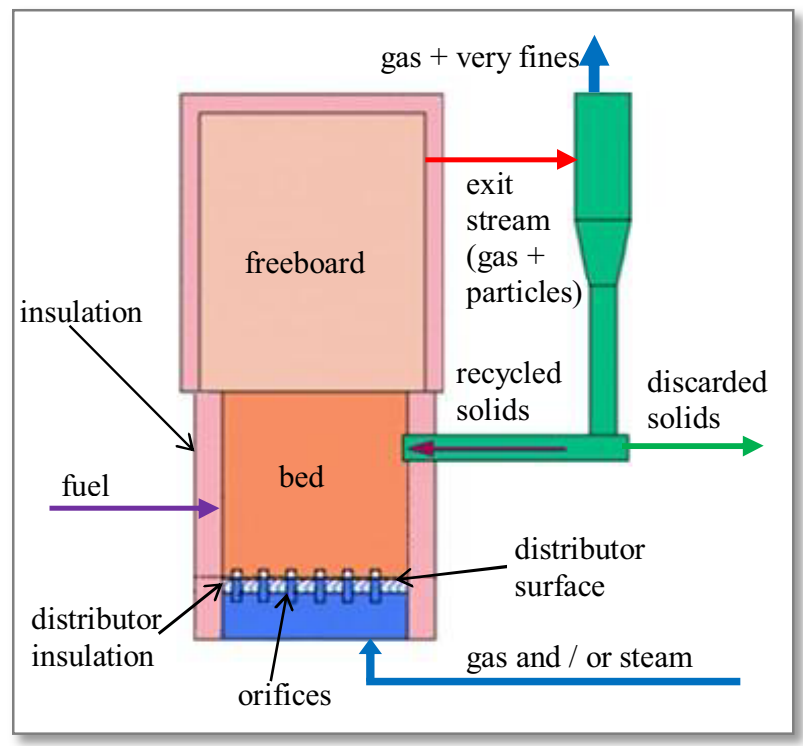

Fig. 4. The fluidized bed system considered by the CeSFaMB simulator [8]

CeSFaMB allows to determine the following operating parameters of the fluidized systems: [8-10]:

- temperature profile,

- particle-size distribution profiles,

- concentration and mass flow profiles of 20 gas components ( $\mathrm{Ar}, \mathrm{CO}_{2}, \mathrm{CO}, \mathrm{O}_{2}, \mathrm{~N}_{2}, \mathrm{H}_{2} \mathrm{O}, \mathrm{H}_{2}, \mathrm{CH}_{4}$, $\mathrm{SO}_{2}, \mathrm{NO}, \mathrm{N}_{2} \mathrm{O}, \mathrm{NO}_{2}, \mathrm{HCN}, \mathrm{C}_{2} \mathrm{H}_{6}, \mathrm{H}_{2} \mathrm{~S}, \mathrm{NH}_{3}, \mathrm{C}_{2} \mathrm{H}_{4}$,
$\left.\mathrm{C}_{3} \mathrm{H}_{6}, \mathrm{C}_{3} \mathrm{H}_{8}, \mathrm{C}_{6} \mathrm{H}_{6}\right)$ and tar throughout the bed in the emulsion and bubble phases

- velocity of the bubbles in the bed,

- diameter of bubbles depending on the height of the fluidized bed,

- the minimum fluidization velocity,

- superficial velocities in the bed and freeboard,

- mass flow of gases in the bed,

- mass flow of particles,

- void fractions in the bed and freeboard.

\subsection{Research methodology}

The experimental studies were carried out in three tests in which the CLC unit is operated stably. In each test, the velocity of the gas was changed in the air reactor. The study aimed to determine the effect of change of gas velocity in the air reactor on the basic parameters of the CLC system.

Table 3. Main operational conditions of the FB-CLC-SF unit

\begin{tabular}{|c|c|c|c|}
\hline & Test No. 1 & Test No. 2 & Test No. 3 \\
\hline $\begin{array}{l}\text { Gas flux in air reactor, } \\
\qquad\left[{ }^{\mathrm{x}} 3600^{-1} \mathrm{~m}^{3} \mathrm{~s}^{-1}\right]\end{array}$ & 9.00 & 21.84 & 25.67 \\
\hline $\begin{array}{l}\text { Gas flux in fuel reactor, } \\
{\left[{ }^{\mathrm{x}} 3600^{-1} \mathrm{~m}^{3} \mathrm{~s}^{-1}\right]}\end{array}$ & 8.6 & 8.6 & 8.6 \\
\hline Temperature, $[\mathrm{K}]$ & 1123 & 1123 & 1123 \\
\hline $\begin{array}{l}\text { Absolute pressure } \\
\text { below the gas } \\
\text { distributor in air } \\
\text { reactor, }[\mathrm{Pa}]\end{array}$ & 104727 & 105391 & 105739 \\
\hline $\begin{array}{l}\text { Absolute pressure } \\
\text { below the gas } \\
\text { distributor in fuel } \\
\text { reactor, }[\mathrm{Pa}]\end{array}$ & 104863 & 105350 & 105768 \\
\hline $\begin{array}{l}\text { Total mass of solids in } \\
\text { the air reactor }[\mathrm{kg}]\end{array}$ & 2.69 & 2.44 & 2.38 \\
\hline $\begin{array}{l}\text { Total mass of solids in } \\
\text { the fuel reactor }[\mathrm{kg}]\end{array}$ & 2.00 & 2.09 & 2.14 \\
\hline
\end{tabular}

Modeling the dynamics of fluidized bed for CLC process performed using a CeSFaMB software. Since the geometry is rather complex: Air Reactor (with the Circulation Fluidizing Bed approach) and Fuel Reactor (with the Bubbling Fluidizing Bed approach) were considered separately and boundary conditions between these two main parts of the system were used to link them.

The method of modeling CLC process using CeSFaMB simulator was presented in the papers $[3,5]$. These articles show the results for the CLC cold model where the process is carried out at a temperature of $25^{\circ} \mathrm{C}$. In contrast, this work presents the results for CLC hot model - at a temperature of $850{ }^{\circ} \mathrm{C}$.

The main operating parameters for these tests, including the information on the gas flux, pressure and 
temperature as well as the total mass of circulating solids are given in Table 3.

\section{Results and discussion}

\subsection{Model validation}

Numerical simulations were carried out taking into account the process conditions during experimental tests. The comparison and verification of the calculation and experiment results involves the following parameters:

- main pressure losses,

- solids recirculation flux,

- void fractions,

- superficial gas velocity,

- gas mass flow rate,

- bubble diameter,

- rising velocity of gas bubbles.

\subsubsection{Main pressure losses and solids recirculation flux}

The average pressure losses across the beds for tests No. $1-3$, predicted by the model as well as the errors of the predictions are given in Table 4. The relative errors between experimental and calculated results are lower than $10 \%$.

Table 4. Pressure loss across the bed, [Pa]

\begin{tabular}{|c|c|c|c|}
\hline & $\begin{array}{c}\text { Air } \\
\text { Reactor }\end{array}$ & $\begin{array}{c}\text { Fuel } \\
\text { Reactor - } \\
\text { Chamber I }\end{array}$ & $\begin{array}{c}\text { Fuel } \\
\text { Reactor - } \\
\text { Chamber II }\end{array}$ \\
\hline Test No. 1 & 2819.54 & 1971.31 & 1971.31 \\
Err [\%] & 1.05 & 0.95 & 0.95 \\
\hline Test No. 2 & 2699.34 & 2245.90 & 2245.90 \\
Err [\%] & 10.03 & 0.18 & 0.18 \\
\hline Test No. 3 & 2711.59 & 2315.16 & 2315.16 \\
Err [\%] & 2.52 & 0.19 & 0.19 \\
\hline \multicolumn{4}{|r}{}
\end{tabular}

Total mass of solids recycled to the bed from the cyclone system in the main cycle equal $0.0026 \mathrm{~kg} \mathrm{~s}^{-1}$, $0.0033 \mathrm{~kg} \mathrm{~s}^{-1}$ and $0.0034 \mathrm{~kg} \mathrm{~s}^{-1}$, for tests No. 1, 2 and 3, respectively. The relative errors between experimental and calculated results are lower than $1 \%$.

\subsubsection{Void fractions}

The dense fluidized bed is formed in the lower part of the reaction chamber. By contrast, the lean region is located above the dense region and covers a predominant part of the chamber [11-14].

The comparison between experimentally determined and predicted by the model void fractions in dense region in the air reactor and fuel reactor is given in Figures 5 and 6. A similar comparison in lean region in the air reactor and fuel reactor is shown in Figures 7 and 8 .
The relative errors between experimental and calculated results are lower than $12 \%$ for dense zone and $1 \%$ for lean region, respectively.

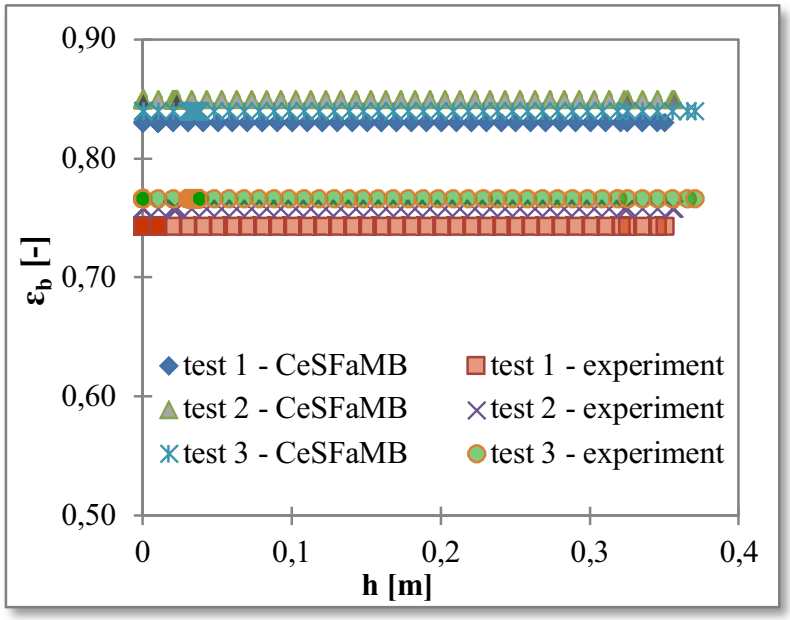

Fig. 5. Comparison between desired and predicted void fractions in dense region of the air reactor

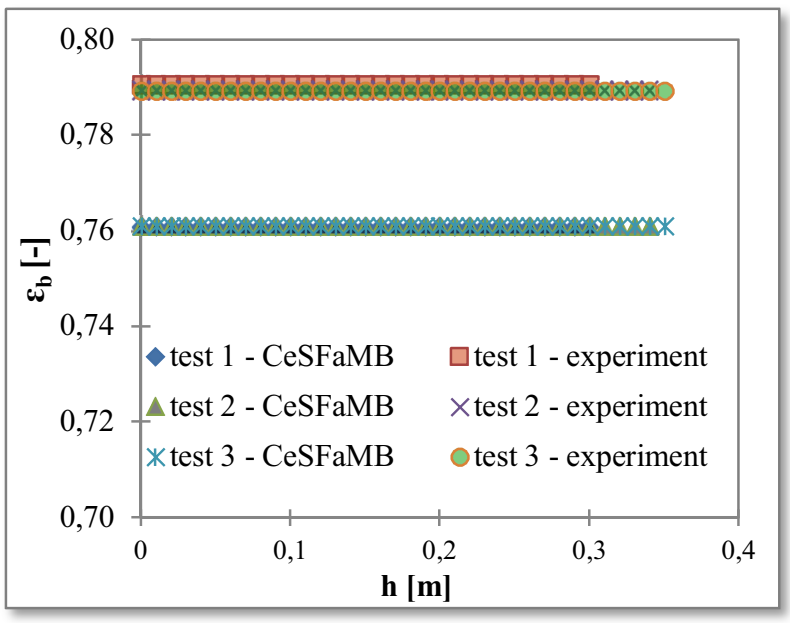

Fig. 6. Comparison between desired and predicted void fractions in dense region of the fuel reactor

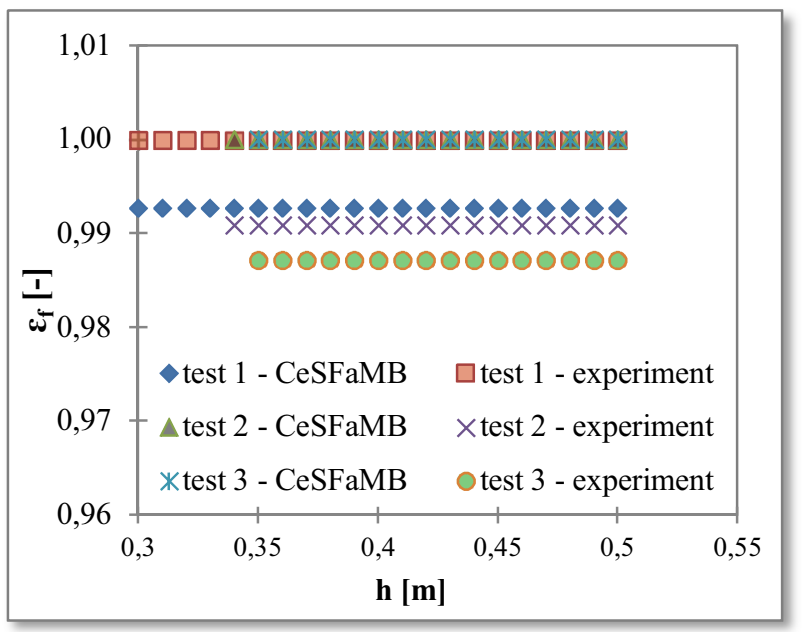

Fig. 7. Comparison between desired and predicted void fractions in lean region of the air reactor 


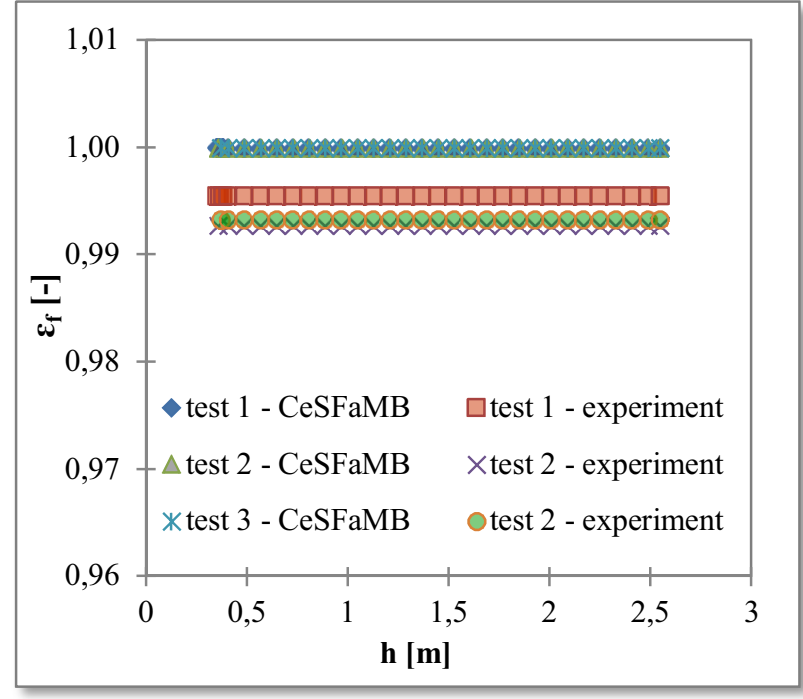

Fig. 8. Comparison between desired and predicted void fractions in lean region of the fuel reactor

The height of the bed is for each test in the air reactor are as follows: $0.35 \mathrm{~m}$ (test 1), $0.36 \mathrm{~m}$ (test 2), $0.37 \mathrm{~m}$ (test 3) and fuel reactor: $0.30 \mathrm{~m}$ (test 1), $0.34 \mathrm{~m}$ (test 2), $0.35 \mathrm{~m}$ (test 3 ), respectively.

\subsubsection{Superficial gas velocity and gas mass flow rate}

The superficial gas velocity depends on the geometry of the reaction chamber whereas the gas mass flow rate is highly dependent on the process temperature [5].

The calculation results are shown in Figures 9 and 10. The maximum relative errors between experimental and calculated superficial gas velocities for the dense bed region of AR and FR do not exceed 2\% and $5 \%$, respectively.

The maximum relative errors of gas mass flow rate estimation are located within the range of $\pm 5 \%$ compared to the experimental data. This comparison is shown in the Figures 11 and 12.

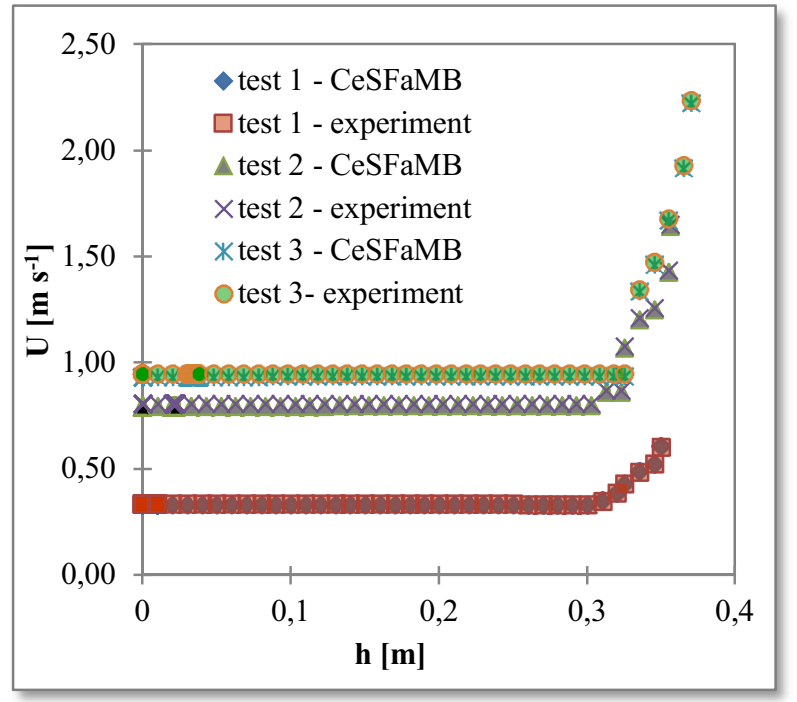

Fig. 9. Comparison between desired and predicted superficial gas velocity in dense bed region of air reactor

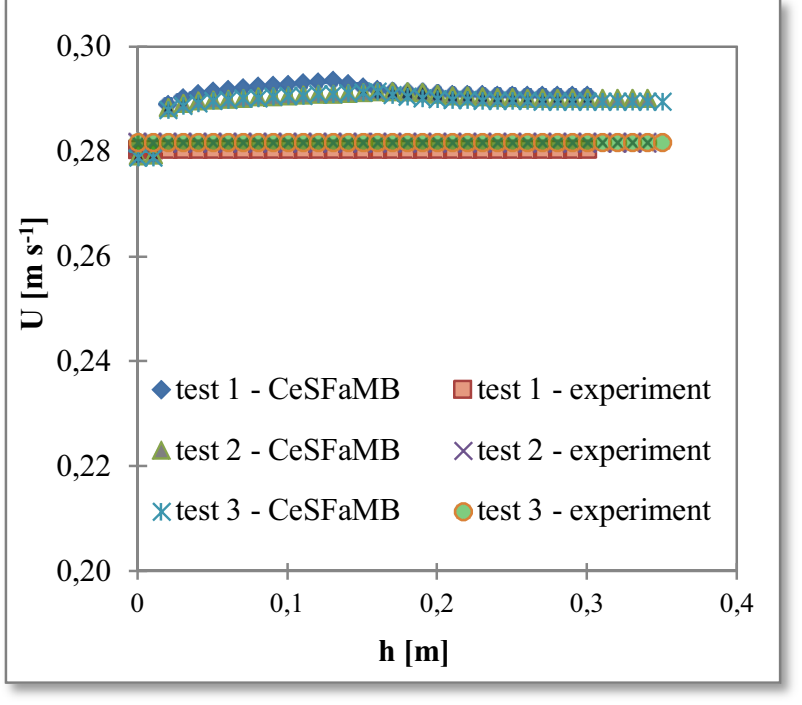

Fig. 10. Comparison between desired and predicted superficial gas velocity in dense bed region of fuel reactor

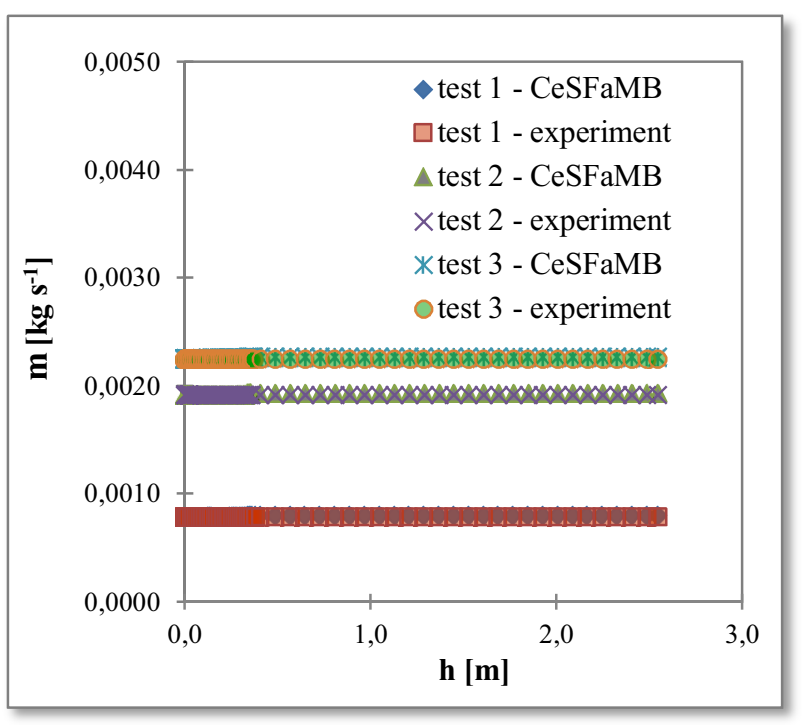

Fig. 11. Comparison between desired and predicted gas mass flow rate in the air reactor

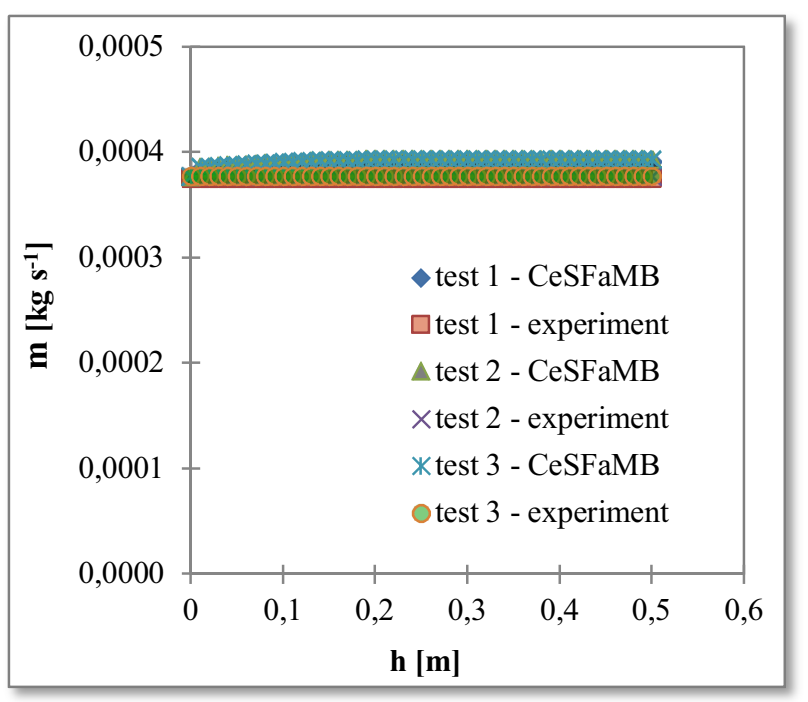

Fig. 12. Comparison between desired and predicted gas mass flow rate in the fuel reactor 


\subsubsection{Bubble diameter and rising velocity of gas bubbles}

In the bubbling and circulating fluidized bed the increase of bubbles diameter occurs with the height of the reaction chamber. Similarly, the rising velocity of gas bubbles increases with the height of the reaction chamber. Furthermore, the rising velocity of gas bubbles is dependent on the bubble diameter. These correlations are described by the following formulas $[3,15]$ :

$$
\begin{gathered}
d_{B}=0.430\left(U-U_{m f}\right) 0.4(h+0.1272) 0.8 g^{-0.2} \\
U_{B}=U-U_{m f}+0.711\left(g d_{B}\right)^{0.5}
\end{gathered}
$$

The comparison between experimentally determined and predicted by the model for bubble diameter and rising velocity of gas bubbles are shown in Figures 13-16.

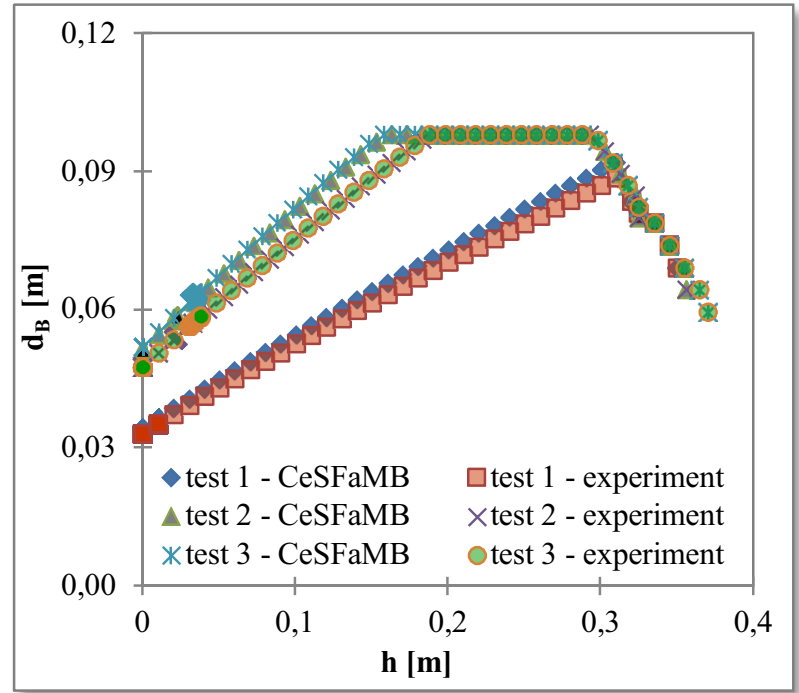

Fig. 13. Comparison between desired and predicted bubble diameter in dense bed of the air reactor

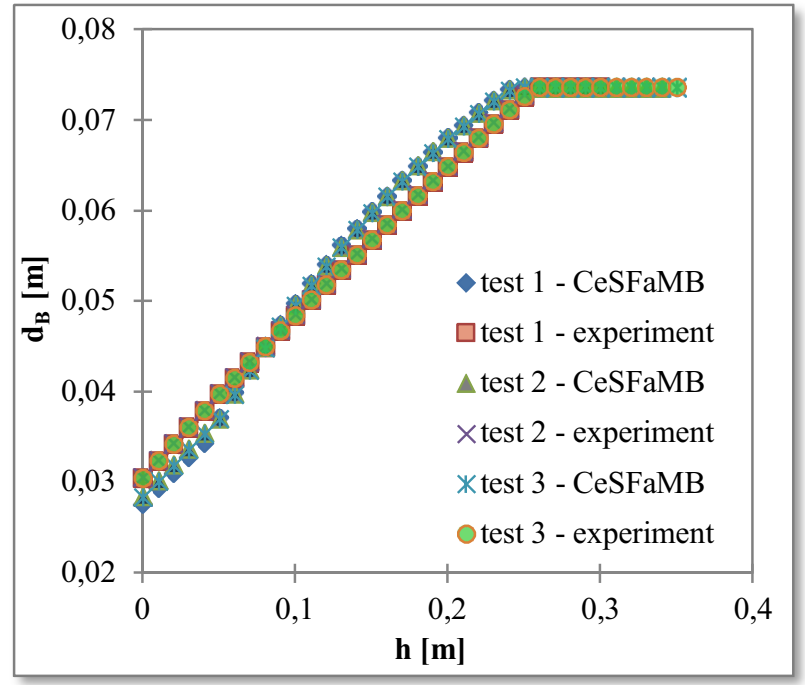

Fig. 14. Comparison between desired and predicted bubble diameter in the fuel reactor.

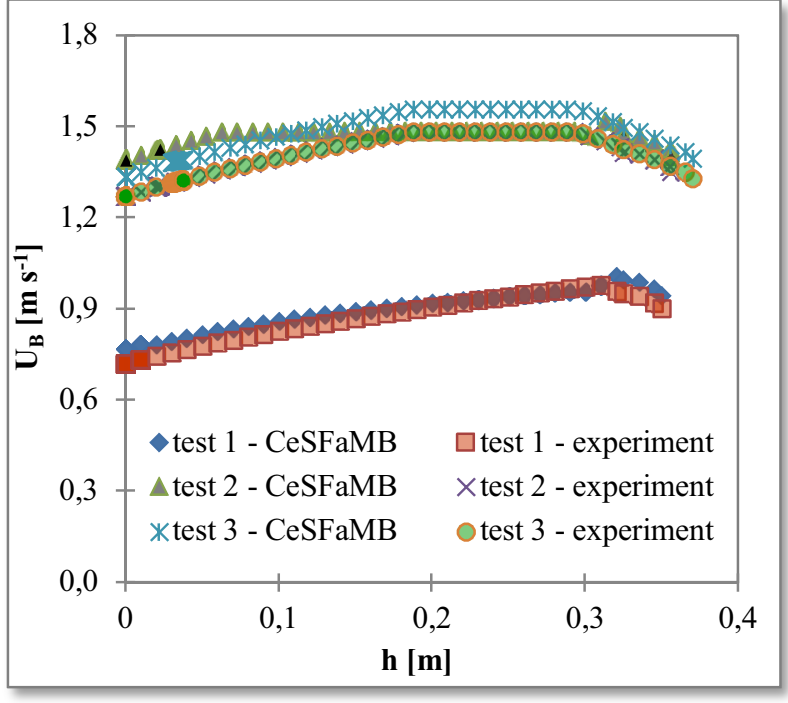

Fig. 15. Comparison between desired and predicted rising velocity of bubble in the air reactor.

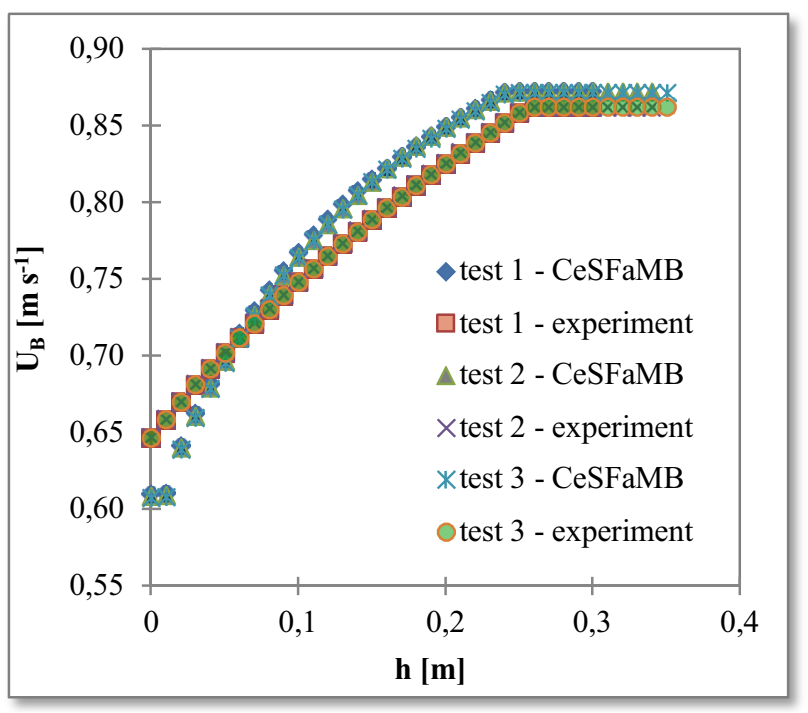

Fig. 16. Comparison between desired and predicted rising velocity of bubble in the fuel reactor

The calculated results do not exceed $10 \%$ compared to the experimental data, for bubble diameter and velocity of a bubble rise.

\subsection{Empirical models for basic dynamic parameters in CLC process}

The successfully validated mathematical model allows to determine the influence of the superficial gas velocity on the following basic dynamic parameters of a CLC process [15]:

- solid circulating rate $\left(\mathrm{G}_{\mathrm{S}}\right)$ in the air reactor,

- number of a particle cycles in air and fuel reactor,

- particles residence time in air and fuel reactor,

- mass of solids in air and fuel reactor.

The influence of the superficial gas velocity on solid circulating rate is given in Figure 17. An increase in 
superficial gas velocity in air reactor causes an increase in the solids circulating rate. This dependence can be described by the following formula (3):

$$
G_{S}=1.91 e^{0.36 v^{A R}}
$$

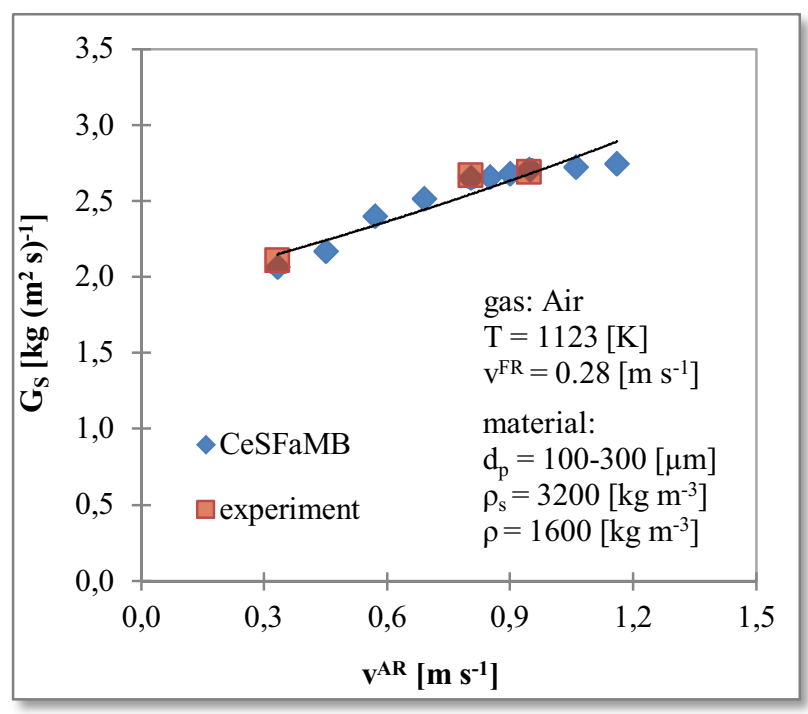

Fig. 17. Solid circulating rate versus superficial gas velocity in the air reactor

The relations of the superficial gas velocity and number of cycles in air and fuel reactors are given in Figures 18 and 19. The analyzed relations is described in equations (4 and 5):

$$
\begin{aligned}
& n_{c}^{A R}=3.02 e^{-0.12 v^{A R}} \\
& n_{c}{ }^{F R}=4.62 e^{-0.12 v^{A R}}
\end{aligned}
$$

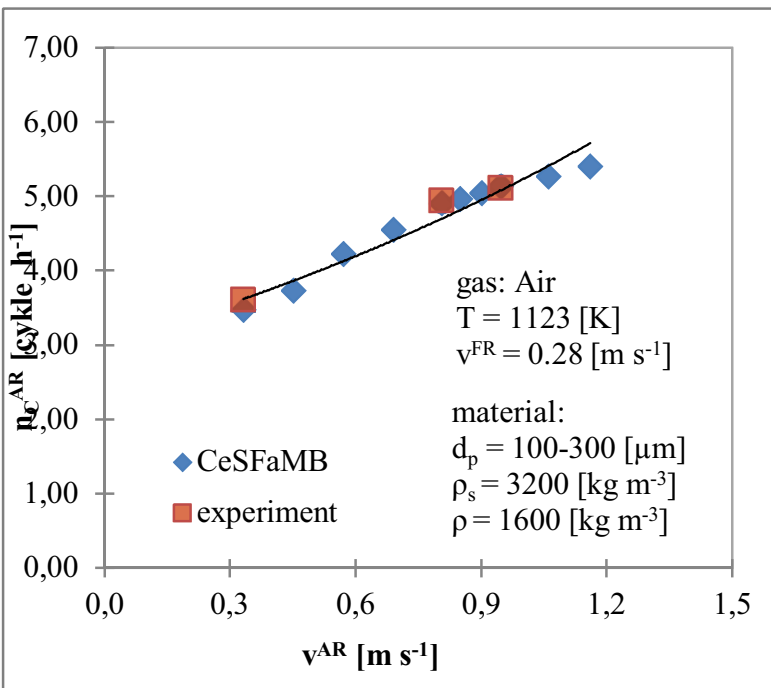

Fig. 18. The number of cycles in air reactor versus superficial gas velocity in the air reactor

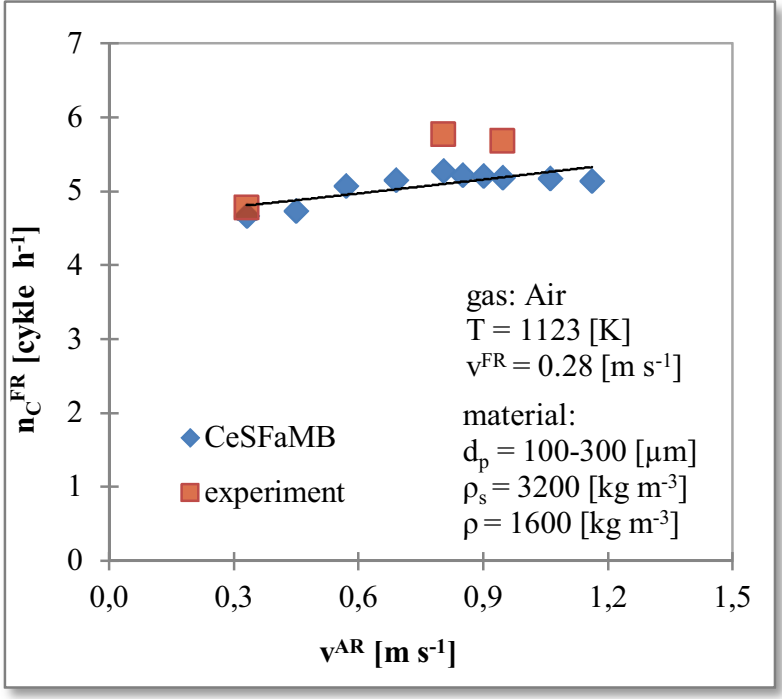

Fig. 19. The number of cycles in fuel reactor versus superficial gas velocity in the air reactor

The results of the reduction in residence time of particles both in air and fuel reactors are shown in Figures 20 and 21. This can be described by the following correlations:

$$
\begin{aligned}
& t_{R}^{A R}=1193 e^{-0.6 v^{A R}} \\
& t_{R}^{F R}=780 e^{-0.12 v^{A R}}
\end{aligned}
$$

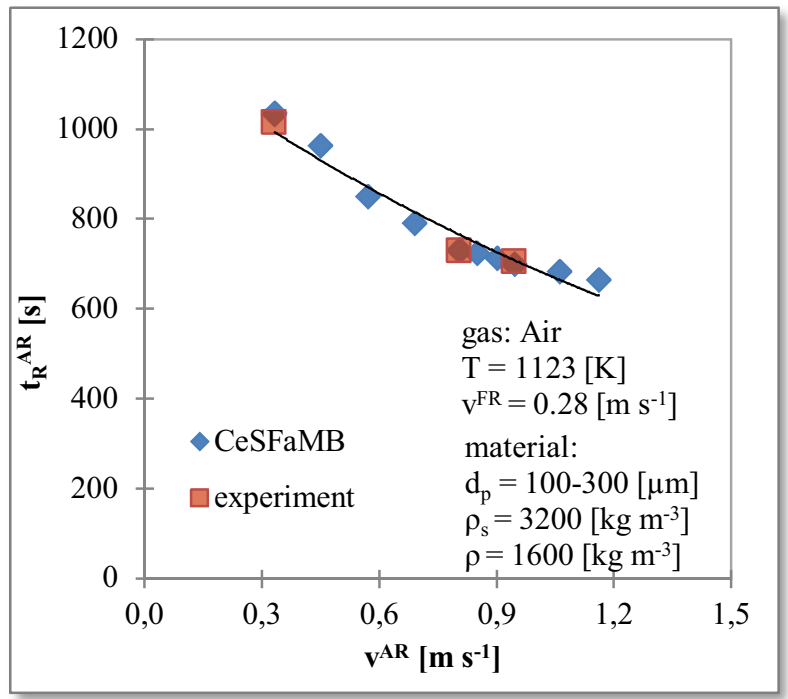

Fig. 20. The particles' residence time in air reactor versus superficial gas velocity in the air reactor 


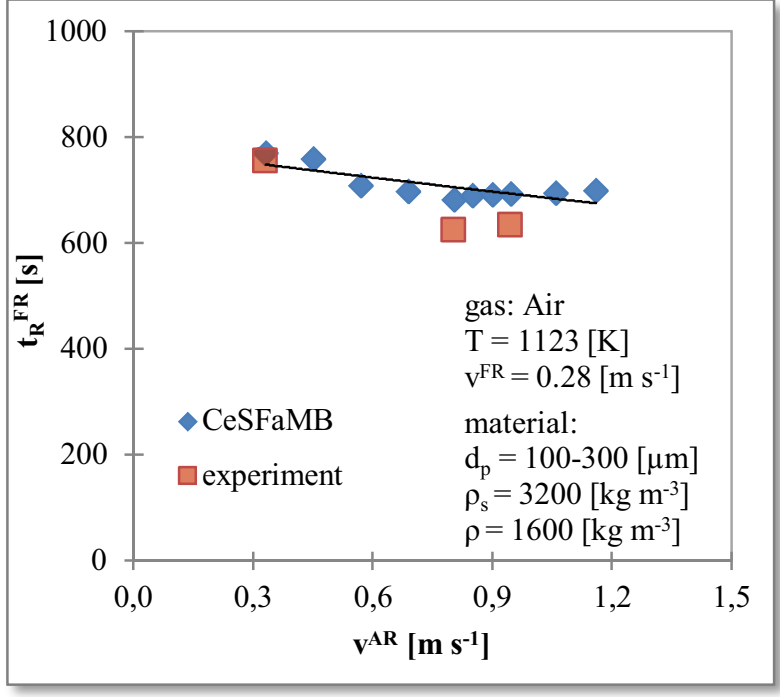

Fig. 21. The particles' residence time in fuel reactor versus superficial gas velocity in the air reactor

The dependences between superficial gas velocity and mass of solids contained in reactors are given in Figures 22 and 23.

The increase of the superficial gas velocity in air reactor causes the decrease in the total mass of solids contained in air reactor (Fig. 22) and an increase in the total mass in fuel reactor (Fig. 23). These behaviour are given in the forrmulas 8 and 9:

$$
\begin{aligned}
& m^{A R}=0.48 v^{A R}+2.84 \\
& m^{F R}=0.51 v^{A R}+1.85
\end{aligned}
$$

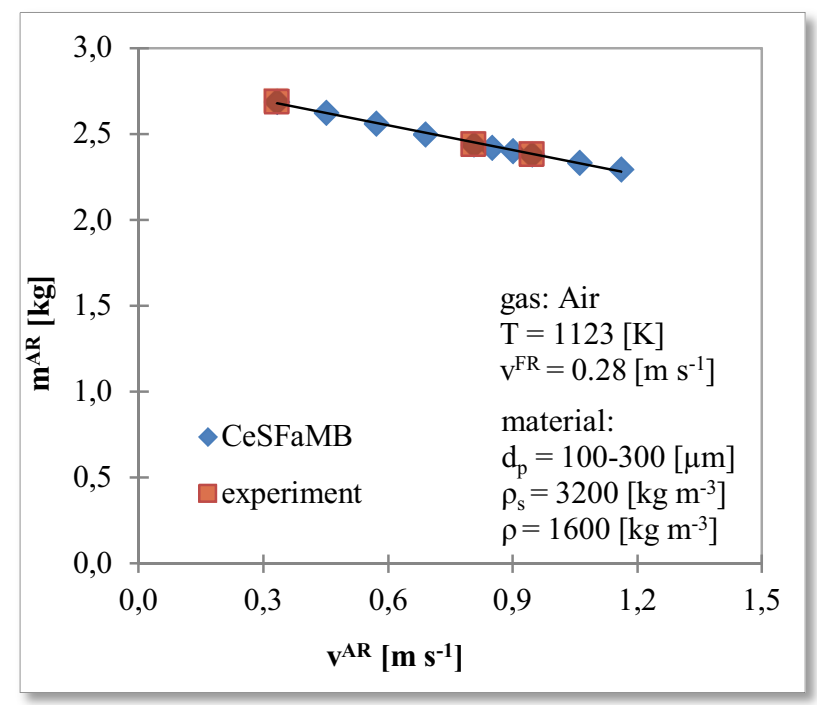

Fig. 22. The total mass in air reactor versus the superficial gas velocity in the air reactor

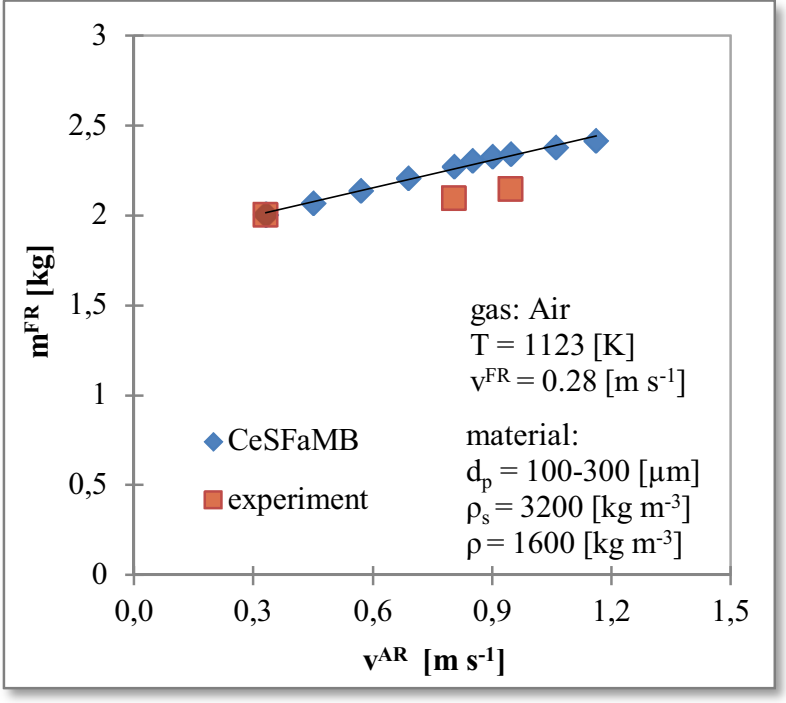

Fig. 23. The total mass in fuel reactor versus superficial gas velocity in the air reactor.

\section{Summary and Conclusions}

The first results of numerical simulations of the dynamic fluidized bed for the hot model of FB-CLC-SF unit are discussed in the paper. The simulations are carried out by the use of CeSFaMB Simulator. The standard operating conditions for the bubbling and circulating fluidized bed are used during the study.

A successfull validated model allows to carry out the simulation of system operation and determine the influence of the superficial gas velocity on the solids circulating rate, number of a particle cycles, particles residence time, as well as mass of solids in air and fuel reactor.

The increase of the superficial gas velocity in air reactor causes the increase in the solid circulating rate, number of cycles in both reactors, total mass in fuel reactor and decrease in the particles' residence time in both reactors, as well as total mass in air reactor.

The comparison of the experiment and calculations results involves the following parameters: main pressure losses, solids recirculation flux, void fractions, superficial gas velocity, gas mass flow rate, bubble diameter and rising velocity of gas bubbles. The validation of the model showed that the maximum relative error between the simulations and experiment results does not exceed $12 \%$, which confirms the correctness of the CLC model. Therefore, the CeSFaMB simulator is a useful tool for the analysis of fluidization dynamics in CLC units.

\section{List of symbols}

$\mathrm{d}$ - diameter, $\mathrm{m}$

$\mathrm{g}-$ acceleration of gravity, $\mathrm{m} \mathrm{s}^{-2}$

$\mathrm{h}$ - vertical coordinate, $\mathrm{m}$

Gs - solid circulating rate, $\mathrm{kg} \mathrm{m}^{-2} \mathrm{~s}^{-1}$

$\mathrm{m}$ - mass of solids, $\mathrm{kg}$

$t_{R}$ - particles' residence time, $s$

$\mathrm{U}$ - velocity, $\mathrm{m} \mathrm{s}^{-1}$ 
$\varepsilon$ - voidage, -

$\mathrm{n}_{\mathrm{C}}-$ number of cycles in the reactors, cycles $\mathrm{h}^{-1}$

\section{Subscripts}

$\mathrm{b}$ - bed,

B - bubbles,

$\mathrm{f}$ - freeboard,

$\mathrm{mf}$ - minimum fluidization conditions

$\mathrm{p}$ - particles

\section{Acronyms}

AR - Air Reactor

FB-CLC-SF - Fluidized-Bed Chemical-Looping -

Combustion of Solid-Fuels,

CeSFaMB - Comprehensive Simulator of Fluidized and

Moving Bed equipment,

CLC - Chemical Looping Combustion,

CLOU - Chemical looping with Oxygen Uncoupling,

FR - Fuel Reactor,

iG-CLC - In-situ Gasification Chemical Looping.

The Project "Innovative Idea for Combustion of Solid Fuels via Chemical Looping Technology" (Agreement No. POL-NOR/235083/104/2014) is funded from Norway Grants in the Polish-Norwegian Research Programme operated by the National Centre for Research and Development. CCS 2013 Call "New innovative solutions for $\mathrm{CO}_{2}$ capture". The support is gratefully acknowledged.

\section{References}

1. E. Ksepko, M. Sciazko, P. Babinski, Studies on the redox reaction kinetics of $\mathrm{Fe}_{2} \mathrm{O}_{3}-\mathrm{CuO} / \mathrm{Al}_{2} \mathrm{O}_{3}$ and $\mathrm{Fe}_{2} \mathrm{O}_{3} / \mathrm{TiO}_{2}$ oxygen carriers, Applied Energy 115, 374-383 (2014)

2. K. Kulicki, T. Czakiert, A. Żyłka, S. Jankowska, J. Krzywański, W. Nowak, Characteristics of operating the fluidized bed CLC cold model, Energy Market (Rynek Energii) 6 (121), 35-40 (2015)

3. A. Żyłka, J. Krzywański, T. Czakiert, K. Kulicki, S. Jankowska, W. Nowak, Modeling for Chemical Looping Combustion of Solid Fuels, Energy Market (Rynek Energii) 1 (122), 75-79 (2016)

4. E. Ksepko, Perovskite-type $\mathrm{Sr}\left(\mathrm{Mn}_{1-x} \mathrm{Ni}_{x}\right) \mathrm{O}_{3}$ materials and their chemical-looping oxygen transfer properties, International Journal of Hydrogen Energy 39, 8126-8137 (2014)

5. A. Żyłka A., J. Krzywański, T. Czakiert, K. Kulicki, S. Jankowska, W. Nowak, Reducing $\mathrm{CO}_{2}$ emissions - Combating climate change, Numerical modeling of fluidized bed combustion of solid fuels in chemical looping using CeSFaMB software, Czestochowa University of Technology, Monographs Series No. 308, 220-234 (2016)

6. T. Czakiert, K. Kulicki, J. Krzywanski, A. Zylka, S. Jankowska, W. Nowak, First Experience in Operation of Cold Model of FB-CLC-SF (FluidizedBed Chemical-Looping-Combustion Solid-Fuels) Facility, [in:] Chaouki J., Berruti F., Bi X., Cocco R.
(Eds.) Fluidization XV, ECI Symposium Series (2016)

7. J. Adanez, A. Abad, G. Garcia-Labiano, P. Gayan, F. Luis F., Progress in chemical-looping combustion and reforming technologies, Progress in Energy Combustion Science, 38(2), 215-282 (2012)

8. Marcio L.de Souza-Santos, Solid Fuels Combustion and Gasification. Modeling, Simulation, and Equipment Operation (2005)

9. Marcio L. de Souza-Santos, Comprehensive Simulator (CSFMB) Applied to Circulating Fluidized Bed Boilers and Gasifiers, The Open Chemical Engineering Journal 2, 106-118, (2008)

10. Marcio L. de Souza-Santos, CSFB applied to fluidized-bed gasification of special fuels, Fuel 88, 826-833 (2009)

11. J. Krzywański, R. Rajczyk, W. Nowak, Model research of gas emissions from a lignite and biomass co-combustion in a large scale CFB boiler, Chemical and Process Engineering, 35, (2), 217-231 (2014)

12. W. Muskała, J. Krzywański, T. Czakiert, W. Nowak, The Research of CFB boiler operation for oxygenenhanced dried lignite combustion, Energy Market (Rynek Energii), 1 (92), 172-176 (2011).

13. KK. Win, W. Nowak, H. Matsuda, M. Hasatani, Z. Bis, J. Krzywański, W. Gajewski, Transport Velocity of Coarse Particles in Multi - Solid Fluidized Bed, Journal of Chemical Engineering of Japan, 28, 5, 535-540 (1995).

14. W. Muskała, J. Krzywański, R. Rajczyk, M. Cecerko, B. Kierzkowski, W. Nowak, W. Gajewski, Investigation of Erosion in CFB Boilers, Energy Market (Rynek Energii), 2 (87), 97 - 102, (2010)

15. J. Krzywanski, A. Żyłka, T. Czakiert, K. Kulicki, S. Jankowska, W. Nowak, $A 1.5 D$ model of a complex geometry laboratory scale fuidized bed CLC equipment, Powder Technology, DOI: 10.1016/j.powtec.2016.09.041 (in press) 